\title{
Validity of carbohydrate, glycaemic index and glycaemic load data obtained using a semi-quantitative food-frequency questionnaire
}

\author{
Alan Winston Barclay ${ }^{1}$, Victoria Mary Flood ${ }^{1}{ }^{2}$, Jennie Cecile Brand-Miller ${ }^{1}$ and \\ Paul Mitchell ${ }^{2, *} \dagger$ \\ ${ }^{1}$ Human Nutrition Unit, University of Sydney, Sydney, New South Wales, Australia: ${ }^{2}$ Department of \\ Ophthalmology (Centre for Vision Research, Westmead Millennium Institute, Westmead Hospital), \\ University of Sydney, Sydney, New South Wales, Australia
}

Submitted 19 January 2007: Accepted 22 May 2007: First published online 24 October 2007

\begin{abstract}
Objective: To assess the ability of a food-frequency questionnaire (FFQ) to rank Australians according to their intake of total carbohydrate, sugar, starch, fibre, glycaemic index (GI) and glycaemic load (GL).

Design: Cross-sectional sample from a population cohort.

Setting: Two postcode areas west of Sydney, Australia.

Subjects: From 1992 to 1994, a total of 2868 older Australians provided dietary data using a 145-item Willett-derived FFQ. A representative sub-sample of 78 subjects completed three 4-day weighed food records (WFRs). Pearson and Spearman correlations, Bland-Altman plots and weighted kappa values were calculated.

Results: Compared with the WFR, the FFQ provided higher mean estimates of all nutrients except starch and GI. All Pearson and/or Spearman correlations were greater than 0.5, except for GL. For GI, sugar, starch and fibre, the regression lines from the Bland-Altman analysis indicated a non-significant linear trend $(P=0.07$, $P=0.36, P=0.28$ and $P=0.10$, respectively). For $\mathrm{GL}$ and total carbohydrate, however, there was a significant linear trend $(P=0.006$ and $P<0.0001$, respectively), indicating that as the GL and carbohydrate intake of individuals increased, so did the magnitude of the error between the FFQ and WFR. Weighted kappa values all indicated moderate to good agreement, with the exception of GL which was only fair. The proportions of subjects correctly classified within one quintile for all of the nutrients were over $50 \%$ and gross misclassification was low $(<10 \%)$. Conclusion: This FFQ was able to rank individuals according to their intakes of total carbohydrate, sugar, starch, fibre and GI, but not as well for GL.
\end{abstract}

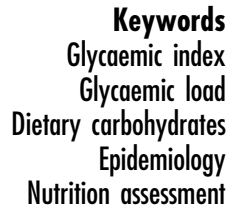

(ycomic index

Glycaemic load

Epidemiology

Nutrition assessment
Valid estimation of habitual food and nutrient intakes is fundamental to the study of relationships between diet and disease. Food-frequency questionnaires (FFQs) are commonly used to estimate dietary intakes in epidemiological studies because they are relatively inexpensive and easy to administer and analyse for large numbers of people ${ }^{1}$. Epidemiological studies most commonly measure associations between dietary intake and disease risk via odds ratios or relative risks. Therefore, FFQs must be able to rank individuals reliably according to their nutrient intakes, so that those with low intakes can be differentiated from those with high intakes for any particular nutrient.

$\dagger$ Correspondence address: University of Sydney Department of Ophthalmology, Eye Clinic Westmead Hospital, Westmead, New South Wales 2145, Australia.
Because there is currently no 'gold standard' for measuring food and nutrient intakes, the relative validity of an FFQ is determined through comparison with other methods such as weighed food records (WFRs) or a series of 24-hour recalls, which have their own, but largely unrelated, errors of measurement ${ }^{1}$. The most common means of assessing agreement between different methods has been to calculate correlation coefficients ${ }^{2}$. However, the calculation of weighted kappa values assessing agreement between tertiles, quartiles or quintiles of nutrient intakes has also been frequently used ${ }^{2}$. More recently, the Bland-Altman method $^{3}$ has been suggested as a more appropriate way of assessing agreement between different dietary assessment tools, although this assertion has been challenged ${ }^{4}$. It has recently been suggested that in order to thoroughly validate an FFQ, 
a variety of statistical methods should be used, including correlations, weighted kappa values and the BlandAltman method ${ }^{2}$.

Accurate assessment of habitual dietary intake is of importance because Australia and many other nations are experiencing an epidemic of diet-related conditions such as overweight and obesity, type 2 diabetes, cardiovascular disease and several major cancers ${ }^{5-7}$. Research to date has identified relationships between excessive energy, saturated fat, alcohol and sodium intakes, and insufficient dietary fibre and antioxidant intakes, and many of these lifestyle-related diseases ${ }^{6}$. There is currently no evidence that high dietary carbohydrate intakes increase the risk of developing these diseases, independent of total energy intake $^{6}$. There is growing evidence, however, that diets with either a high glycaemic index (GI) or a high glycaemic load (GL) are linked to the development of obesity $^{8-11}$, type 2 diabetes ${ }^{12-14}$, cardiovascular disease ${ }^{15-17}$, and cancer of the colon ${ }^{18-20}$ and breast ${ }^{21-24}$.

The underlying mechanism linking high-GI/GL diets to the risk of developing these lifestyle-related diseases is thought to be the postprandial glycaemic response. Both the quality and the quantity of carbohydrate determine the postprandial glycaemic response to a food or meal ${ }^{25}$. By definition, the GI compares equal quantities of available carbohydrate in foods and provides a measure of carbohydrate quality or glycaemic potential. The GL, on the other hand, is a function of a food's GI and its total available carbohydrate content and is defined as: $\mathrm{GL}=\mathrm{GI}(\%) \times$ carbohydrate $(\mathrm{g})$. The higher the GL, the greater the expected elevation in postprandial blood glucose levels ${ }^{26}$.

To date, over 30 prospective cohort studies have investigated the link between GI, GL and the risk of developing chronic lifestyle-related disease using FFQs. Surprisingly, to our knowledge, none has directly assessed the ability of an FFQ to rank individuals accurately according to their GI and GL values. Instead, most have used total carbohydrate, dietary fibre and other carbohydrate fractions as surrogate measures. The lack of direct validation of these measures could be a significant cause of the widespread variation in associations found between GI, GL and disease risk, and deserves further investigation.

We aimed in the present study to assess the relative validity of the Blue Mountains Eye Study (BMES) FFQ by comparing it with the BMES WFR, to determine how well it ranked older Australians according to their mean daily GI, GL and carbohydrate intakes.

\section{Methods}

\section{The BMES}

The methods used in the BMES have been described previously ${ }^{27,28}$. Briefly, the present study concerns the baseline study (BMES I), which identified 4433 eligible non-institutionalised permanent residents, aged 49 years or more, in a door-to-door census conducted during 1991, of whom 3654 (82\%) participated in detailed examinations during the period 1992-1994. The study was approved by both the Western Sydney Area Health Service and the University of Sydney Human Ethics Committees, and written informed consent was obtained from all participants. Of 779 (18\%) persons identified in the census who did not participate, $353(8 \%)$ permitted only a brief interview, 148 (3\%) refused, 210 (5\%) had moved out of the area, and 68 (1.5\%) had died before the examinations were conducted. The overall response was therefore $82 \%$. Baseline differences between participants and non-participants were minimal ${ }^{29}$.

All study participants were invited to attend a local clinic for a medical history and examination, which included anthropometry, history of chronic lifestyle-related diseases and associated risk factors. Fasting pathology tests, including blood lipids and plasma glucose, were obtained for $88 \%$ of the 3654 residents at a second visit ${ }^{29}$.

\section{The FFQ}

The 145-item semi-quantitative FFQ was modified for the Australian diet and vernacular from an earlier FFQ of Willett et $a l^{30}$, and included portion size estimates and additional questions about the type of breakfast cereals, to increase the accuracy of the GI estimates. The FFQ has previously been validated against a series of WFRs for most macro- and micronutrients, but not for GI or GL ${ }^{29,31}$. Participants attempting the FFQ numbered 3267 (89\%) and, of these, 2868 were usable (79\% of those examined, $88 \%$ of those who attempted the FFQ). FFQs with more than 10 items missing ${ }^{28}$ or with implausible, extreme values $(<2090 \mathrm{~kJ} /$ day or $>16720 \mathrm{~kJ} /$ day) were excluded. Respondents of the FFQ were asked about the foods eaten in the previous 12 months, and an allowance for seasonal variation of fruit and vegetables was made during analyses by weighting seasonal fruits and vegetables.

\section{Subjects in the validation study}

In 1994, a random selection of 186 BMES subjects, weighted to include more older people (65-85 years), were invited to take part in the validation study. Each subject was required to complete three 4-day WFRs approximately four months apart. Average time from completion of the first FFQ was 6 months. Of the 150 people who agreed to participate, 139 began recording food intake and 121 provided completed, usable first WFRs. Of these, 100 completed a second usable WFR, 4 months later, and 90 completed a third WFR, 8 months after the first. Of these, 12 were excluded because they either did not complete a second FFQ or the WFRs were incomplete $^{29}$. A final total of 78 subjects $(52 \%$ of those 
who agreed to participate) completed all three 4-day WFRs, which were included in the secondary analysis of GI, GL and carbohydrates.

\section{Dietary data}

A dietitian coded data from the semi-quantitative FFQ into a custom-built database (DBASE IV; Borland International Inc., 1991), which incorporated the Australian food composition tables (NUTTAB 90) ${ }^{32}$ plus published GI values using the glucose $=100$ scale $^{26}$. Additional GI data were obtained from the Sydney University Glycemic Index Research Service (SUGiRS) online database (www. glycemicindex.com). The same dietitian coded the WFR data into the FoodWorks (Xyris Software, 2006) dietary analysis software, using the same food composition tables and GI values. In total, $88.9 \%$ of the GI values were obtained direct from published values, while the remaining $11.1 \%$ were interpolated from similar food items.

The overall GI of each participant's diet was calculated by summing the weighted GI of individual foods in the diet, with the weighting proportional to the contribution of individual foods to total carbohydrate intake. The GL of each food item was calculated by multiplying each food's GI by the amount of available carbohydrate $(\mathrm{g})$ per serving: $\mathrm{GL}=\mathrm{GI}(\%) \times$ carbohydrate $(\mathrm{g})$. Overall dietary GL was then determined as the product of the food's GL and the participant's frequency of consumption, summed over all foods.

\section{Statistical analysis}

Concurrent validity of the FFQ compared with the WFRs was assessed using four primary methods:

1. Comparison of group means.

2. Pearson product-moment and Spearman ranked correlations.

3. Bland-Altman limits of agreement $(\mathrm{LOA})^{3}$, in which the mean agreement between the two methods, i.e. FFQ and WFR, was calculated. The LOA define the limits within which $95 \%$ of these differences are expected to fall (mean \pm two standard deviations of the differences). The differences between the two methods were plotted against the average of the two methods. Any dependency between the two methods was tested by fitting the regression line of differences $\left(\mathrm{H}_{\mathrm{O}}: \beta=0, \alpha=0.05\right)$, i.e. ideally if the two methods are equally variable, the correlation between the differences would equal zero. Natural $\log (\ln )$ transformation was performed since the dietary data were skewed, as recommended by Bland and Altman ${ }^{3}$.

4. Joint classification of nutrient intake assessed by the FFQ and the average of the three WFRs was assessed using quintiles of intake for each nutrient from the FFQ and WFR, respectively. The proportion grossly misclassified applied when one dietary assessment method classified the individual's intake into the lowest quintile and the other method classified it into the highest quintile. Cohen's weighted kappa values were calculated comparing quintiles of intake for each nutrient from the FFQ and WFR ${ }^{33}$.

For all methods, all nutrients were adjusted for total energy using the residual method ${ }^{34}$. Energy adjustment was done separately for each FFQ and the average of the three WFRs.

All statistical analyses were performed using SPSS version 14.0.0 (SPSS Inc., 2002).

\section{Results}

\section{Study participants}

Individuals who completed a usable FFQ were, on average, 1 year younger than the study population as a whole, but they were no more likely to have serious eye disease (data not shown). The proportion of men (45\%) and women $(55 \%)$ participating in the validation and BMES studies was similar. By design, those participating in the validation study were older than those participating in the BMES study, by a mean difference of approximately 5 years (age 65 years in BMES and 70 years in the validation study; $P<0.0001)$.

\section{Comparison of group means}

The mean daily intakes of carbohydrate fractions, GI and GL for the average of the three 4-day WFRs and the FFQ are shown in Table 1 . With the exception of starch and GI, the FFQ provided higher mean estimates of all of the nutrients compared with the WFR. With the exception of GL, all differences were statistically significant (Wilcoxon signed-rank sum test: carbohydrate, $P=0.012$; sugar, $P<0.0001$; starch, $P<0.0001$; fibre, $P<0.0001$; GI, $P<0.0001$; GL, $P=0.3327$ ).

\section{Correlations}

Pearson product-moment correlation and Spearman rank correlation (crude, adjusted for energy, ln-transformed and deattenuated) for comparisons of nutrient intakes from the FFQ and the three 4-day WFRs are shown in Table 1. All of the nutrients had deattenuated Pearson or Spearman correlations greater than 0.5 , with the exception of GL. The correlation between total carbohydrate and GL was 0.92 for the FFQ and 0.89 for the WFR.

\section{Bland-Altman analysis}

Bland-Altman analyses were performed for GI, GL and all carbohydrate fractions. Figures 1 and 2 illustrate the findings for GI and GL, respectively (other carbohydrate fractions not illustrated). For GI, sugar, starch and fibre, the regression lines indicated a non-significant linear 
Table 1 Assessment of agreement between the weighed food record (WFR) and the food-frequency questionnaire (FFQ) for carbohydrate fractions, glycaemic index (Gl) and glycaemic load (GL) in the Blue Mountains Eye Study

\begin{tabular}{|c|c|c|c|c|c|c|c|}
\hline Parameter & $\begin{array}{c}\text { Total } \\
\text { carbohydrate }\end{array}$ & Sugar & Starch & Fibre & Gl‡ & GL $\ddagger$ & Target $^{4}$ \\
\hline \multicolumn{8}{|l|}{ Intake $(\mathrm{g})$, mean (SD) } \\
\hline $\operatorname{WFR}(n=78)$ & $215(58)$ & $104(39)$ & $109(33)$ & $24(7)$ & $58(3)$ & $123(33)$ & \\
\hline $\mathrm{WFR}^{\star}(n=78)$ & 207 (53) & $97(56)$ & $105(39)$ & $23(13)$ & $58(6)$ & 119 (33) & \\
\hline $\mathrm{FFQ}(n=78)$ & $229(72)$ & $124(50)$ & $103(33)$ & $29(12)$ & $56(4)$ & $129(41)$ & \\
\hline $\mathrm{FFQ}^{*}(n=78)$ & $218(80)$ & $114(72)$ & $98(41)$ & 27 (18) & $56(7)$ & $123(46)$ & \\
\hline FFQ $(n=2868)$ & $234(76)$ & $128(52)$ & $103(36)$ & $28(12)$ & $57(4)$ & $132(44)$ & \\
\hline $\mathrm{FFQ}^{\star}(n=2868)$ & $234(40)$ & $128(35)$ & $103(26)$ & $28(10)$ & $57(4)$ & $132(24)$ & \\
\hline $\begin{array}{l}\text { Mean difference } \\
\quad\left(\mathrm{FFQ}^{\star}-\mathrm{WFR}^{\star}\right)(\mathrm{g})\end{array}$ & $\begin{array}{c}14.8 \\
(P=0.0001)\end{array}$ & $\begin{array}{c}19.9 \\
(P=0.0002)\end{array}$ & $\begin{array}{c}-6.2 \\
(P=0.001)\end{array}$ & $\begin{array}{c}5.2 \\
(P<0.0001)\end{array}$ & $\begin{array}{l}-1.9 \\
(P=0.0002)\end{array}$ & $(P=0.0003)$ & \\
\hline Ratio FFQ*/WFR* & 1.05 & 1.18 & 0.93 & 1.17 & 0.96 & 1.03 & \\
\hline Crude Pearson correlation & 0.43 & 0.42 & 0.36 & 0.52 & 0.41 & 0.40 & \\
\hline Pearson correlation* & 0.55 & 0.53 & 0.40 & 0.67 & 0.40 & 0.38 & \\
\hline Deattenuated Pearson correlation* & 0.62 & 0.62 & 0.44 & 0.79 & 0.42 & 0.44 & $>0.5$ \\
\hline Crude Spearman rank correlation & 0.44 & 0.49 & 0.47 & 0.59 & 0.46 & 0.39 & \\
\hline Spearman rank correlation* & 0.48 & 0.46 & 0.47 & 0.70 & 0.53 & 0.32 & \\
\hline $\begin{array}{l}\text { Deattenuated Spearman rank } \\
\text { correlation* }\end{array}$ & 0.55 & 0.53 & 0.51 & 0.82 & 0.57 & 0.38 & $>0.5$ \\
\hline Mean difference (FFQ-WFR)* & 0.05 & 0.16 & -0.07 & 0.16 & -0.03 & 0.03 & \\
\hline $\mathrm{LOA}^{*}$ & $-0.26,0.36$ & $-0.41,0.72$ & $-0.50,0.36$ & $-0.35,0.66$ & $-0.17,0.10$ & $-0.34,0.39$ & \\
\hline Antilog mean difference $(F F Q-W F R)^{\star}(g)$ & 1.05 & 1.17 & 0.93 & 1.17 & 0.97 & 1.03 & \\
\hline Antilog of $\mathrm{LOA}^{*}(\mathrm{~g})$ & $1.43,0.77$ & $2.06,0.66$ & $1.43,0.61$ & $1.94,0.70$ & $1.11,0.84$ & $1.48,0.71$ & \\
\hline $\begin{array}{l}\text { Correctly classified in the same quintile } \\
(\%)^{\star}\end{array}$ & 38.5 & 28.2 & 39.7 & 45.0 & 40.0 & 31.0 & \\
\hline Classified within one quintile $(\%)^{*}$ & 71.8 & 69.2 & 74.3 & 84.6 & 74.0 & 65.0 & \\
\hline Grossly misclassified $(\%)^{\star}+$ & 2.6 & 1.3 & 3.8 & 0.0 & 1.0 & 6.0 & $<10$ \\
\hline Weighted kappa* & 0.43 & 0.41 & 0.47 & 0.73 & 0.53 & 0.30 & $>0.4$ \\
\hline
\end{tabular}

LOA - limits of agreement.

*Energy-adjusted using the residual method ${ }^{34}$ and In-transformed.

tOne dietary method classifies intake into the bottom quintile; the other method classifies intake into the top quintile. $\ddagger$ Units $=\%$.

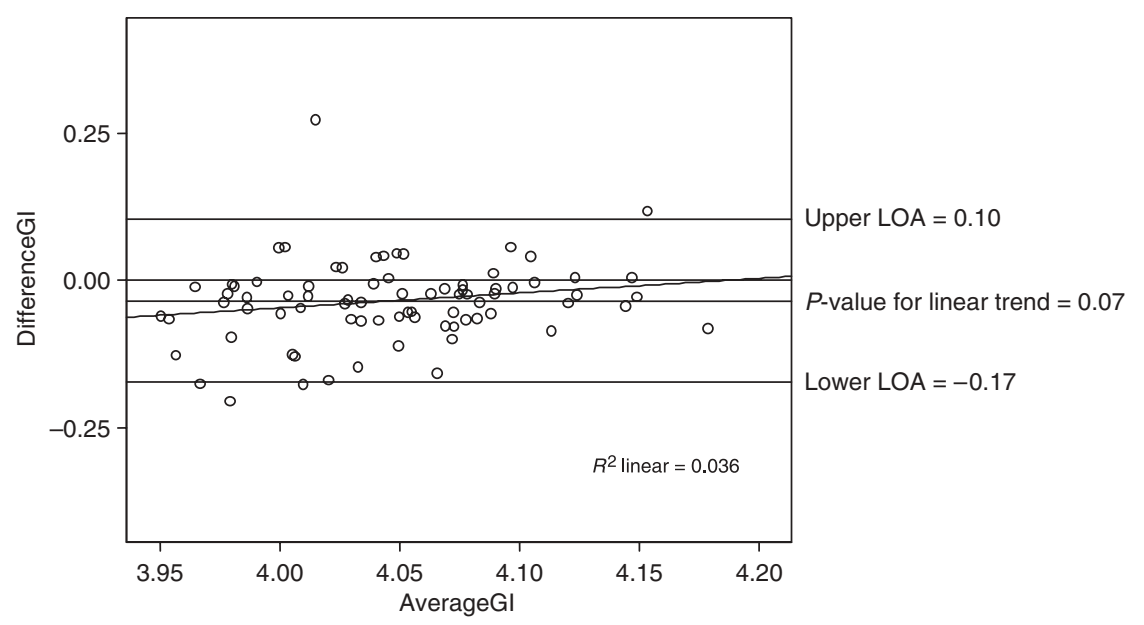

Fig. 1 Bland-Altman plot assessing the agreement between the food-frequency questionnaire (FFQ) and the weighed food record (WFR) for glycaemic index (GI) after In transformation and adjustment for energy (DifferenceGI - difference between GI measured by the FFQ and GI measured by the WFR; AverageGI - mean of GI measured by the FFQ and GI measured by the WFR; LOA limit of agreement)

trend $(P=0.07, \quad P=0.360, \quad P=0.277$ and $P=0.097$, respectively). For GL and total carbohydrate, however, the regression lines indicated a significant linear trend ( $P=0.006$ and $P<0.0001$, respectively), suggesting dependency existed between the difference of the two methods and the average of the two methods; as indivi- duals' GL and total carbohydrate increased, the magnitude of the error between the FFQ and WFR increased.

\section{Classification into categories of consumption}

The proportion of subjects correctly classified within one quintile category for all of the nutrients was over 50\% 


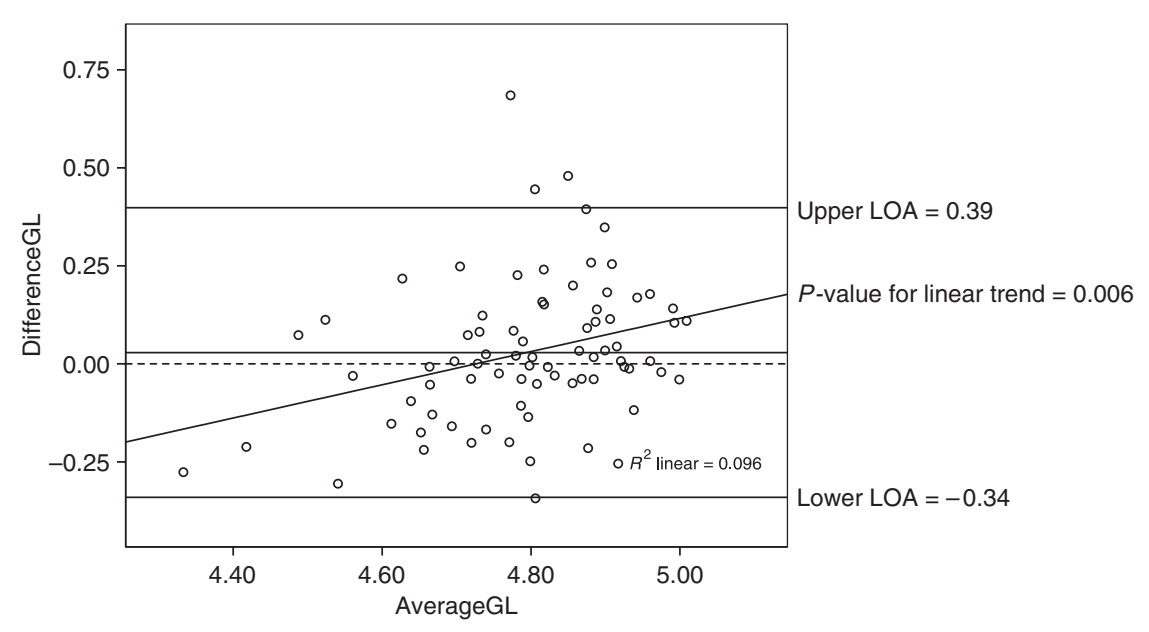

Fig. 2 Bland-Altman plot assessing the agreement between the food-frequency questionnaire (FFQ) and the weighed food record (WFR) for glycaemic load (GL) after In transformation and adjustment for energy (DifferenceGL - difference between GL measured by the FFQ and GL measured by the WFR; AverageGL - mean of GL measured by the FFQ and GL measured by the WFR; LOA - limit of agreement)

(Table 1). Gross misclassification was relatively low, with all nutrients less than 10\%. All weighted kappa values indicated moderate to good agreement, with the exception of GL which was only fair.

\section{Discussion}

This study assessed, using different statistical methods, the validity of a 145 -item semi-quantitative FFQ in a representative sample of older Australians, by comparing carbohydrate intakes, GI and GL values obtained from the FFQ with those derived from three, 4-day WFRs. Comparison of group means, correlation coefficients, Bland-Altman analyses and weighted kappa values showed that this FFQ is capable of ranking individuals according to their total carbohydrate, sugar, starch, dietary fibre and GI intakes, but not as well for their GL. The FFQ had a tendency to overestimate total carbohydrate, sugar, dietary fibre and GL, but not starch and GI. For GL and total carbohydrates, the overestimation was greatest in those with higher intakes.

The BMES FFQ is subject to errors common to these kinds of tools, namely the reliance on long-term memory, a relatively restricted list of foods, interpretation of frequencies and average serving sizes, and a poor ability of some individuals to estimate and describe their usual food intake. While WFRs do not rely on memory, limited food lists or average serving sizes, they do place a substantial burden on individuals and their families, which may inadvertently affect usual food intake. In addition to this, food intake may vary considerably over the course of a week, month and even more so over a year ${ }^{1}$. However, our analyses demonstrate that for total carbohydrate, sugar, starch, dietary fibre and GI, the estimates of both methods were sufficiently similar to indicate an ability to rank individuals reliably according to their habitual intakes of these essential nutrients.

The BMES FFQ was not originally designed to measure differences in the GI of foods, and the GI values of certain foods like breads and breakfast cereals are very brandspecific. However, Australia has a more extensive GI database than most other countries ${ }^{26}$, minimising this potential source of error. It is likely that the errors associated with estimating the GI, combined with those associated with estimating total carbohydrate, were compounded, resulting in the relatively poor ability of the FFQ to estimate GL.

The generalisability of the results of this validation study to the whole BMES population is considered reasonable. A slightly older age range was deliberately selected for the validation study because we were mainly interested in agerelated diseases less common in younger people and we wanted to be sure of a valid instrument for those individuals who were likely to become cases in our future prospective analyses. The participation rate in the validation study was not high, but acceptable, and the loss to follow-up was not unduly large for such a long-term study with high subject burden ${ }^{29}$.

The results of this validation study have important implications for studies that have used FFQs to investigate associations between dietary carbohydrates, GI, GL and risk of chronic lifestyle-related disease. To our knowledge, none published to date has directly assessed the ability of its FFQ to rank individuals accurately according to their GI and GL values. Instead, the vast majority of studies have used the correlation coefficient for total carbohydrate, and occasionally other carbohydrate fractions, as surrogates.

Brunner et $a l^{35}$ have suggested that a value "of about 0.5 for most nutrients and 0.8 for alcohol between methods is good evidence that the FFQ has the ability to 
rank individuals ... according to nutrient intake'. Indeed, of the 34 prospective cohort studies investigating the link between dietary carbohydrates, GI, GL and chronicdisease risk published by mid-2006 $6^{12,13,15,18,19,21,36-63}$, $24(70 \%)$ have correlations for total carbohydrate that meet this target; as did our own FFQ. While the correlation between our FFQ and WFR was similarly acceptable for GI, it was not for GL, and this was confirmed by further statistical analysis. Therefore, our data suggest that just because an FFQ has a correlation for total carbohydrate with a WFR of $\geq 0.5$, we cannot automatically assume that it is able to rank individuals according to their GI and GL. Its ability to do so needs to be assessed independently, using a variety of different statistical methods ${ }^{2}$.

Of concern, four ${ }^{21,48,51,53}$ of the 34 studies (12\%) investigating the relationship between dietary carbohydrates, GI, GL and chronic disease risk were not validated for any available carbohydrate fraction, let alone GI or GL. All four of these studies were based on the Canadian National Breast Screening Study. The self-administered dietary questionnaire used in this study was validated for a variety of nutrients that at the time were thought to be related to cancer aetiology including fats, protein and a number of vitamins, with generally acceptable results. However, available carbohydrate was not considered to be a risk factor, and as a consequence was not included in the validation process ${ }^{64}$. A further six (18\%) stu$\operatorname{dies}^{39,40,46,53,56,63}$ had correlation coefficients for total carbohydrates less than 0.5. The ARIC (Atherosclerosis Risk in Communities) study ${ }^{40}$ and the pancreatic cancer study of Michaud et al. ${ }^{56}$ used the original 61-item FFQ of Willett et al., which had an energy-adjusted correlation coefficient for total carbohydrate of 0.45 with a WFR ${ }^{65}$. The breast cancer study of Nielsen et $a l^{46}{ }^{46}$ used an FFQ with an energy-adjusted correlation coefficient for total carbohydrate of $0.47^{66}$. The Insulin Resistance Atherosclerosis Study, reported by Liese et al. ${ }^{62}$ and Mayer-Davis et $a l^{63}$, used an FFQ with an energy-adjusted correlation of only $0.37^{67}$. Finally, the FFQ used in the type 2 diabetes study of Meyer et al. ${ }^{39}$ had an energy-adjusted correlation of $0.45^{68}$. Despite this, all these authors suggested that their FFQs were able to rank individuals according to their GI and GL, and drew conclusions about the effect of GI and/or GL on disease risk on the basis of this assumption which, according to our own analysis, may be unjustified $^{69}$.

\section{Conclusion}

Our validation study of dietary carbohydrates, GI and GL has found that a Willett-derived FFQ used in the BMES can rank individuals according to their intakes of total carbohydrate, sugar, starch, fibre and GI, but less well for GL. To date, studies investigating the link between habitual intake of glycaemic carbohydrate and chronic disease risk have not directly assessed whether their FFQ is able to adequately rank individuals according to their GI and GL, with the majority relying on surrogate measures like correlations with total carbohydrate. Our study has demonstrated that this assumption is not entirely supported, and may have led to some erroneous conclusions. More comprehensive validation techniques that include direct assessment of an FFQ's ability to rank individuals according to their carbohydrate fractions, GI and GL will improve the quality of evidence investigating the effect of these factors on chronic disease risk.

\section{Acknowledgements}

Competing interests: Nil identified.

\section{References}

1 Willett W. Nutritional Epidemiology, 2nd ed. New York: Oxford University Press, 1998.

2 Burley V, Cade J, Margetts B, Thompson R, Warm D. Consensus Document on the Development, Validation and Utilisation of Food Frequency Questionnaires. London: Ministry of Agriculture, Fisheries and Food, 2000; 62 pp.

3 Bland JM, Altman DG. Statistical methods for assessing agreement between two methods of clinical measurement. Lancet 1986; 325(8476): 307-10.

4 Masson LF, McNeill G, Tomany JO, Simpson JA, Peace HS, Wei L, et al. Statistical approaches for assessing the relative validity of a food-frequency questionnaire: use of correlation coefficients and the kappa statistic. Public Health Nutrition 2003; 6(3): 313-21.

5 O'Brien K. Living Dangerously: Australians with Multiple Risk Factors for Cardiovascular Disease. Bulletin No. 24. Canberra: Australian Institute of Health and Welfare, 2005.

6 National Health and Medical Research Council. Food for Health: Dietary Guidelines for Australian Adults. Canberra: Commonwealth of Australia, 2003.

7 Australian Bureau of Statistics (ABS). Causes of Death, Australia, 2005. Catalogue No. 3303.0. Canberra: ABS, 24 February 2005.

8 Ma Y, Olendzki B, Chiriboga D, Hebert JR, Li Y, Li W, et al. Association between dietary carbohydrates and body weight. American Journal of Epidemiology 2005; 161(4): 359-67.

9 Pawlak DB, Kushner JA, Ludwig DS. Effects of dietary glycaemic index on adiposity, glucose homoeostasis, and plasma lipids in animals. Lancet 2004; 364(9436): 778-85.

10 Ebbeling CB, Leidig MM, Sinclair KB, Hangen JP, Ludwig DS. A reduced-glycemic load diet in the treatment of adolescent obesity. Archives of Pediatrics \& Adolescent Medicine 2003; 157(8): 773-9.

11 Spieth LE, Harnish JD, Lenders CM, Raezer LB, Pereira MA, Hangen SJ, et al. A low-glycemic index diet in the treatment of pediatric obesity. Archives of Pediatrics \& Adolescent Medicine 2000; 154(9): 947-51.

12 Salmeron J, Ascherio A, Rimm EB, Colditz GA, Spiegelman D, Jenkins DJ, et al. Dietary fiber, glycemic load, and risk of NIDDM in men. Diabetes Care 1997; 20(4): 545-50.

13 Salmeron J, Manson JE, Stampfer MJ, Colditz GA, Wing AL, Willett WC. Dietary fiber, glycemic load, and risk of noninsulin-dependent diabetes mellitus in women. JAMA: Journal of the American Medical Association 1997; 277(6): 472-7.

14 Schulze MB, Liu S, Rimm EB, Manson JE, Willett WC, Hu FB. Glycemic index, glycemic load, and dietary fiber intake and 
incidence of type 2 diabetes in younger and middle-aged women. American Journal of Clinical Nutrition 2004; 80(2): 348-56.

15 Oh K, Hu FB, Cho E, Rexrode KM, Stampfer MJ, Manson JE, et al. Carbohydrate intake, glycemic index, glycemic load, and dietary fiber in relation to risk of stroke in women. American Journal of Epidemiology 2005; 161(2): 161-9.

16 Liu S, Willett WC, Stampfer MJ, Hu FB, Franz M, Sampson L, et al. A prospective study of dietary glycemic load, carbohydrate intake, and risk of coronary heart disease in US women. American Journal of Clinical Nutrition 2000; 71(6): 1455-61.

17 Amano Y, Kawakubo K, Lee JS, Tang AC, Sugiyama M, Mori K. Correlation between dietary glycemic index and cardiovascular disease risk factors among Japanese women. European Journal of Clinical Nutrition 2004; 58(11): 1472-8.

18 Michaud DS, Fuchs CS, Liu S, Willett WC, Colditz GA, Giovannucci E. Dietary glycemic load, carbohydrate, sugar, and colorectal cancer risk in men and women. Cancer Epidemiology, Biomarkers \& Prevention 2005; 14(1): 138-47.

19 Higginbotham S, Zhang ZF, Lee IM, Cook NR, Giovannucci E, Buring JE, et al. Dietary glycemic load and risk of colorectal cancer in the Women's Health Study. Journal of the National Cancer Institute 2004; 96(3): 229-33.

20 Franceschi S, Dal Maso L, Augustin L, Negri E, Parpinel M, Boyle $\mathrm{P}$, et al. Dietary glycemic load and colorectal cancer risk. Annals of Oncology 2001; 12(2): 173-8.

21 Silvera SA, Jain M, Howe GR, Miller AB, Rohan TE. Dietary carbohydrates and breast cancer risk: a prospective study of the roles of overall glycemic index and glycemic load. International Journal of Cancer 2005; 114(4): 653-8.

22 Frazier AL, Li L, Cho E, Willett WC, Colditz GA. Adolescent diet and risk of breast cancer. Cancer Causes \& Control 2004; 15(1): 73-82.

23 Holmes MD, Liu S, Hankinson SE, Colditz GA, Hunter DJ, Willett WC. Dietary carbohydrates, fiber, and breast cancer risk. American Journal of Epidemiology 2004; 159(8): 732-9.

24 Augustin LS, Dal Maso L, La Vecchia C, Parpinel M, Negri E, Vaccarella S, et al. Dietary glycemic index and glycemic load, and breast cancer risk: a case-control study. Annals of Oncology 2001; 12(11): 1533-8.

25 Sheard NF, Clark NG, Brand-Miller JC, Franz MJ, Pi-Sunyer FX, Mayer-Davis E, et al. Dietary carbohydrate (amount and type) in the prevention and management of diabetes: a statement by the American Diabetes Association. Diabetes Care 2004; 27(9): 2266-71.

26 Foster-Powell K, Holt SH, Brand-Miller JC. International table of glycemic index and glycemic load values: 2002. American Journal of Clinical Nutrition 2002; 76(1): 5-6.

27 Attebo K, Mitchell P, Smith W. Visual acuity and the causes of visual loss in Australia. The Blue Mountains Eye Study. Ophthalmology 1996; 103(3): 357-64.

28 Smith W, Mitchell P, Reay EM, Webb K, Harvey PW. Validity and reproducibility of a self-administered food frequency questionnaire in older people. Australian and New Zealand Journal of Public Health 1998; 22(4): 456-63.

29 Mitchell P, Smith W, Wang JJ, Cumming RG, Leeder SR, Burnett L. Diabetes in an older Australian population. Diabetes Research and Clinical Practice 1998; 41(3): $177-84$.

30 Willett WC, Sampson L, Browne ML, Stampfer MJ, Rosner B, Hennekens $\mathrm{CH}$, et al. The use of a self-administered questionnaire to assess diet four years in the past. American Journal of Epidemiology 1988; 127(1): 188-99.

31 Flood VM, Smith WT, Webb KL, Mitchell P. Issues in assessing the validity of nutrients data obtained from a food-frequency questionnaire: folate and vitamin $\mathrm{B}_{12}$ examples. Public Health Nutrition 2004; 7(6): 751-6.

32 Department of Community Services and Health. NUTTAB 90 Nutrient Data Table for Use in Australia. Canberra: Australian Government Publishing Service, 1990.

33 Fleiss JL. The Measurement of Interrater Agreement. Statistical Methods for Rates and Proportions. New York: Jon Wiley \& Sons, 1981; 212-36.

34 Willett W, Stampfer MJ. Total energy intake: implications for epidemiologic analyses. American Journal of Epidemiology 1986; 124(1): 17-27.

35 Brunner E, Stallone D, Juneja M, Bingham S, Marmot M. Dietary assessment in Whitehall II: comparison of $7 \mathrm{~d}$ diet diary and food-frequency questionnaire and validity against biomarkers. British Journal of Nutrition 2001; 86(3): 405-14.

36 Hodge AM, English DR, O’Dea K, Giles GG. Glycemic index and dietary fiber and the risk of type 2 diabetes. Diabetes Care 2004; 27(11): 2701-6.

37 Schulze MB, Liu S, Rimm EB, Manson JE, Willett WC, Hu FB. Glycemic index, glycemic load, and dietary fiber intake and incidence of type 2 diabetes in younger and middle-aged women. American Journal of Clinical Nutrition 2004; 80(2): 348-56.

38 Zhang C, Liu S, Solomon CG, Hu FB. Dietary fiber intake, dietary glycemic load, and the risk for gestational diabetes mellitus. Diabetes Care 2006; 29(10): 2223-30.

39 Meyer KA, Kushi LH, Jacobs Jr DR, Slavin J, Sellers TA, Folsom AR. Carbohydrates, dietary fiber, and incident type 2 diabetes in older women. American Journal of Clinical Nutrition 2000; 71(4): 921-30.

40 Stevens J, Ahn K, Juhaeri Houston D, Steffan L, Couper D. Dietary fiber intake and glycemic index and incidence of diabetes in African-American and white adults: the ARIC study. Diabetes Care 2002; 25(10): 1715-21.

41 Liu S, Willett WC, Stampfer MJ, Hu FB, Franz M, Sampson L, et al. A prospective study of dietary glycemic load, carbohydrate intake, and risk of coronary heart disease in US women. American Journal of Clinical Nutrition 2000; 71(6): 1455-61.

42 van Dam RM, Visscher AW, Feskens EJ, Verhoef P, Kromhout D. Dietary glycemic index in relation to metabolic risk factors and incidence of coronary heart disease: the Zutphen Elderly Study. European Journal of Clinical Nutrition 2000; 54(9): 726-31.

43 Jonas CR, McCullough ML, Teras LR, Walker-Thurmond KA, Thun MJ, Calle EE. Dietary glycemic index, glycemic load, and risk of incident breast cancer in postmenopausal women. Cancer Epidemiology, Biomarkers \& Prevention 2003; 12(6): 573-7.

44 Cho E, Spiegelman D, Hunter DJ, Chen WY, Colditz GA, Willett WC. Premenopausal dietary carbohydrate, glycemic index, glycemic load, and fiber in relation to risk of breast cancer. Cancer Epidemiology, Biomarkers \& Prevention 2003; 12(11): 1153-8.

45 Higginbotham S, Zhang ZF, Lee IM, Cook NR, Buring JE, Liu S. Dietary glycemic load and breast cancer risk in the Women's Health Study. Cancer Epidemiology, Biomarkers \& Prevention 2004; 13(1): 65-70.

46 Nielsen TG, Olsen A, Christensen J, Overvad K, Tjonneland A. Dietary carbohydrate intake is not associated with the breast cancer incidence rate ratio in postmenopausal Danish women. Journal of Nutrition 2005; 135(1): 124-8.

47 Giles GG, Simpson JA, English DR, Hodge AM, Gertig DM, Macinnis RJ, Hopper JL. Dietary carbohydrate, fibre, glycaemic index, glycaemic load and the risk of postmenopausal breast cancer. International Journal of Cancer 2006; 118(7): 1843-7.

48 Terry PD, Jain M, Miller AB, Howe GR, Rohan TE. Glycemic load, carbohydrate intake, and risk of colorectal cancer in 
women: a prospective cohort study. Journal of the National Cancer Institute 2003; 95(12): 914-16.

49 Oh K, Willett WC, Fuchs CS, Giovannucci EL. Glycemic index, glycemic load, and carbohydrate intake in relation to risk of distal colorectal adenoma in women. Cancer Epidemiology, Biomarkers \& Prevention 2004; 13(7): 1192-8.

50 Johnson KJ, Anderson KE, Harnack L, Hong CP, Folsom AR. No association between dietary glycemic index or load and pancreatic cancer incidence in postmenopausal women. Cancer Epidemiology, Biomarkers \& Prevention 2005; 14(6): 1574-5.

51 Silvera SA, Rohan TE, Jain M, Terry PD, Howe GR, Miller AB. Glycemic index, glycemic load, and pancreatic cancer risk (Canada). Cancer Causes \& Control 2005; 16(4): 431-6.

52 Folsom AR, Demissie Z, Harnack L. Glycemic index, glycemic load, and incidence of endometrial cancer: the Iowa Women's Health Study. Nutrition and Cancer 2003; 46(2): 119-24.

53 Silvera SA, Rohan TE, Jain M, Terry PD, Howe GR, Miller AB. Glycaemic index, glycaemic load and risk of endometrial cancer: a prospective cohort study. Public Health Nutrition 2005; 8(7): 912-19.

54 Larsson SC, Bergkvist L, Wolk A. Glycemic load, glycemic index and carbohydrate intake in relation to risk of stomach cancer: a prospective study. International Journal of Cancer 2006; 118(12): 3167-9.

55 Holmes MD, Liu S, Hankinson SE, Colditz GA, Hunter DJ, Willett WC. Dietary carbohydrates, fiber, and breast cancer risk. American Journal of Epidemiology 2004; 159(8): 732-9.

56 Michaud DS, Liu S, Giovannucci E, Willett WC, Colditz GA, Fuchs CS. Dietary sugar, glycemic load, and pancreatic cancer risk in a prospective study. Journal of the National Cancer Institute 2002; 94(17): 1293-300.

57 Tsai CJ, Leitzmann MF, Willett WC, Giovannucci EL. Dietary carbohydrates and glycaemic load and the incidence of symptomatic gall stone disease in men. Gut 2005; 54(6): 823-8.

58 Tsai CJ, Leitzmann MF, Willett WC, Giovannucci EL. Glycemic load, glycemic index, and carbohydrate intake in relation to risk of cholecystectomy in women. Gastroenterology 2005; 129(1): 105-12.

59 Chiu CJ, Hubbard LD, Armstrong J, Rogers G, Jacques PF, Chylack Jr LT, et al. Dietary glycemic index and carbohy- drate in relation to early age-related macular degeneration. American Journal of Clinical Nutrition 2006; 83(4): 880-886.

60 Schaumberg DA, Liu S, Seddon JM, Willett WC, Hankinson SE. Dietary glycemic load and risk of age-related cataract. American Journal of Clinical Nutrition 2004; 80(2): 489-95.

61 Chiu CJ, Morris MS, Rogers G, Jacques PF, Chylack Jr LT, Tung W, et al. Carbohydrate intake and glycemic index in relation to the odds of early cortical and nuclear lens opacities. American Journal of Clinical Nutrition 2005; 81(6): 1411-16.

62 Liese AD, Schulz M, Fang F, Wolever TM, D'Agostino Jr RB, Sparks KC, et al. Dietary glycemic index and glycemic load, carbohydrate and fiber intake, and measures of insulin sensitivity, secretion, and adiposity in the Insulin Resistance Atherosclerosis Study. Diabetes Care 2005; 28(12): 2832-8.

63 Mayer-Davis EJ, Dhawan A, Liese AD, Teff K, Schulz M. Towards understanding of glycaemic index and glycaemic load in habitual diet: associations with measures of glycaemia in the Insulin Resistance Atherosclerosis Study. British Journal of Nutrition 2006; 95(2): 397-405.

64 Jain MG, Harrison L, Howe GR, Miller AB. Evaluation of a self-administered dietary questionnaire for use in a cohort study. American Journal of Clinical Nutrition 1982; 36(5): 931-5.

65 Willett WC, Sampson L, Stampfer MJ, Rosner B, Bain C, Witschi $\mathrm{J}$, et al. Reproducibility and validity of a semiquantitative food frequency questionnaire. American Journal of Epidemiology 1985; 122(1): 51-65.

66 Tjonneland A, Overvad K, Haraldsdottir J, Bang S, Ewertz M, Jensen OM. Validation of a semiquantitative food frequency questionnaire developed in Denmark. International Journal of Epidemiology 1991; 20(4): 906-12.

67 Mayer-Davis EJ, Vitolins MZ, Carmichael SL, Hemphill S, Tsaroucha G, Rushing J, et al. Validity and reproducibility of a food frequency interview in a Multi-Cultural Epidemiology Study. Annals of Epidemiology 1999; 9(5): 314-24.

68 Munger RG, Folsom AR, Kushi LH, Kaye SA, Sellers TA Dietary assessment of older Iowa women with a food frequency questionnaire: nutrient intake, reproducibility, and comparison with 24-hour dietary recall interviews. American Journal of Epidemiology 1992; 136(2): 192-200.

69 Barclay AW, Brand-Miller JC. Validity of glycemic index estimates in the Insulin Resistance Atherosclerosis Study: response to Liese et al. Diabetes Care 2006; 29(7): 1718-19. 